\title{
Personality Disorders in Alcohol- Dependent Individuals: Relationship with Alcohol Dependence Severity
}

\author{
U.W. Preuss ${ }^{a} \quad$ M. Johann ${ }^{b} \quad$ C. Fehr ${ }^{d} \quad$ G. Koller ${ }^{c} \quad$ N. Wodarz ${ }^{b} \quad$ V. Hesselbrock ${ }^{f}$ \\ W.M. Wong ${ }^{\text {e }}$ M.Soykac \\ a Department of Psychiatry, Psychotherapy and Psychosomatics, Martin Luther University of Halle-Wittenberg, \\ Halle, ${ }^{b}$ Department of Psychiatry, University of Regensburg, Regensburg, ' Department of Psychiatry, \\ Ludwig Maximilians University, Munich, ${ }^{\mathrm{d}}$ Department of Psychiatry, Johannes Gutenberg University, Mainz, and \\ eAWO Psychiatry Centre, Halle, Germany; ${ }^{\mathrm{f}}$ Department of Psychiatry, University of Connecticut School of Medicine, \\ Farmington, Conn., USA
}

\section{Key Words}

Alcohol dependence $\cdot$ Personality disorders $\cdot$ Severity of alcohol dependence $\cdot$ Comorbidity

\begin{abstract}
The rate of axis II disorders in alcohol-dependent individuals is suggested to be high. The aim of this investigation is to assess the rate of DSM-IV axis II diagnoses in alcohol-dependent inpatients and their correlation with clinical characteristics of alcohol dependence (AD). 1,079 inpatients with DSM-IV AD from three inpatient addiction treatment centers ('qualified detoxification', open psychiatric university hospital wards) were included. Characteristics of AD were obtained using standardized structured interviews. Diagnoses of DSM-IV personality disorders (PDs) were generated with SCID-II-PQ and SCID-II interviews. Alcoholism severity was measured using the number of DSM-IV criteria endorsed and age at first drinking. Approximately $60 \%$ of the sample had at least one PD. However, rates of Axis II disorders differed significantly across centers. The most frequent PDs were obsessive-compulsive, borderline, narcissistic and paranoid PD. Diagnosis of any PD was related to a more severe clinical profile of AD. Regression analyses revealed that obsessivecompulsive PD was related to the number of DSM-IV criteria
\end{abstract}

endorsed while antisocial PD was related to early age at first drinking. The majority of alcohol-dependent individuals had one or more comorbid axis II disorders. Univariate and multivariate analyses indicate that different PDs are related to age at first dinking and alcoholism severity.

Copyright $\odot 2009$ S. Karger AG, Basel

\section{Introduction}

Numerous research reports indicate a high rate of personality disorders (PDs) in alcohol-dependent subjects [1-3]. These findings were supplemented by recent epidemiologic data from the National Epidemiologic Survey on Alcohol and Related Conditions (NESARC) [4] which reported $39.5 \%$ of the alcohol-dependent subjects to have at least one of seven investigated PDs in comparison to $14.8 \%$ of controls. Higher rates of PD diagnoses are often reported from inpatient samples of alcohol-dependent subjects, where the frequency of at least one axis II diagnosis ranged between 25 and 93\% [5]. This wide range of PD comorbidity rates may depend on specific sample characteristics, differences in admission, treatment modalities and diagnostic instruments employed [6].

Ulrich W. Preuss, MD, Department of Psychiatry

Psychotherapy and Psychosomatics, Martin Luther University of Halle-Wittenberg Julius-Kühn-Strasse 7, DE-06097 Halle/Saale (Germany)

Tel. +49 345557 4595, Fax +49345 5573500

E-Mail ulrich.preuss@medizin.uni-halle.de

$\begin{array}{ll}\text { KARGER } & \oplus \text { 2009 S. Karger AG, Basel } \\ \text { Fax +4161306 12 34 } & \text { 1022-6877/09/0154-0188\$26.00/0 } \\ \begin{array}{l}\text { E-Mail karger@karger.ch } \\ \text { www.karger.com }\end{array} & \begin{array}{l}\text { Accessible online at: } \\ \text { www.karger.com/ear }\end{array}\end{array}$


Alcohol-dependent subjects affected by a comorbid PD are reported to more likely be high users of the health care system [7], to receive less alcoholism-specific treatment [8] and to have a more severe course of alcohol dependence $(\mathrm{AD})$ than non-comorbid alcohol-dependent individuals $[9,10]$. Several previous studies also reported an adverse effect of comorbid PDs on treatment compliance and outcome [11-13].

Hitherto, research on this topic mainly focused on the comorbidity of antisocial PD and AD [4] and not the full range of DSM-IV PDs. The more recent epidemiological NESARC study assessed 7 (obsessive-compulsive, paranoid, antisocial, schizoid, avoidant, histrionic and dependent PD) of 12 axis II disorder diagnoses in alcoholdependent individuals [4]. The remaining five axis II disorders may be of importance in the etiology, treatment and prognosis of $\mathrm{AD}$, i.e. borderline personality disorder which is often accompanied with alcohol and substance use disorder (ASUD) [5, 13], and is reported to be related with onset and course of $\mathrm{AD}$ [5].

While there is no unanimous agreement on how to assess 'severity' of $\mathrm{AD}$, item response analysis of alcohol use disorder symptoms has been utilized as a psychometric indicator of severity [14] and suggested that DSM-IV diagnostic criteria for AD form a continuum of severity. However, to the clinician, 'severity' may include additional characteristics of $\mathrm{AD}$ such as refractoriness to treatment, duration of illness, adherence problems, the occurrence of multiple relapses, or the magnitude of individual symptoms presented by their patients [15]. Assessing DSM-IV AD criterion endorsement as a measure of alcoholism severity using the NESARC data set, $6 / 7$ or $7 / 7$ criteria were associated with greater severity across a variety of indicators [15]. Alternative approaches include the age at onset of drinking or measures by the addiction severity index, which have been demonstrated to be useful surrogates for other indicators of severity [16-19].

The first aim of this investigation is to identify the rate of axis II disorders and their relationship with AD characteristics in a larger sample of inpatient alcohol-dependent individuals. Secondly, gender differences in the rate of PDs and $\mathrm{AD}$ characteristics and the influence of $\mathrm{PD}$ comorbidity on $\mathrm{AD}$ severity were investigated.

\section{Patients and Methods}

\section{Sample}

All participants were recruited as inpatients from three addiction treatment wards ('qualified detoxification') of the psychiatric hospitals Ludwig-Maximilians University of Munich $(\mathrm{n}=386)$,
Gutenberg University of Mainz ( $\mathrm{n}=202)$ and University of Regensburg $(n=491)$. All alcohol-dependent subjects $(n=1079)$ were treatment-seeking and admitted through an outpatient motivational group (Munich), an addiction outpatient unit (Regensburg) or for emergency detoxification (Mainz). While the mode of admission is different across hospitals, all three centers offer a 'qualified detoxification' program which not only includes somatic detoxification but also individual and group psychotherapy, counseling for social and financial problems and somatic medical care. All subjects met DSM-IV criteria for AD which were assessed using the German Versions of CIDI/DIA-X (Composite International Diagnostic Interview) [20, 21], in Mainz and Regensburg, or SSAGA (Semi-Structured Assessment on Genetics in Alcoholism) [22], in Munich.

Though different assessment instruments were employed because each ward had a specific measure in evaluating AD, all participating hospitals used the same DSM-IV diagnostic criteria. Furthermore, while no differences in gender $\left(\chi^{2}\right.$ value $=0.87, \mathrm{p}=$ 0.64 ) or age ( $F$ value $=1.18, p=0.31$ ) were detected, a number of $\mathrm{AD}$ characteristics differed significantly across recruitment sites, including recent average daily alcohol intake ( $\mathrm{F}$ value $=4.61, \mathrm{p}=$ 0.01 ) and the number of DSM-IV criteria endorsed ( $F$ value $=$ $39.27, \mathrm{p}<0.001$ ), all of which were higher in subjects from the Regensburg hospital.

While each recruiting hospital enrolled alcohol-dependent subjects consecutively, several individuals underwent some of the assessments but were not included into the study $(\mathrm{n}=430)$ for a number of reasons. A significant percentage of the individuals left the treatment before completing the assessments or were transferred to another psychiatric or somatic ward for acute physical or psychiatric problems. Comparing characteristics of subjects enrolled or not enrolled into the study, while no significant difference in age ( $t$ value $=0.87, p=0.38)$, gender $\left(\chi^{2}\right.$ value $=1.59$, $\mathrm{p}=0.20)$, age at onset of $\mathrm{AD}(\mathrm{t}$ value $=-0.49, \mathrm{p}=0.62)$, duration of $\mathrm{AD}$ ( $\mathrm{t}$ value $=0.88, \mathrm{p}=0.38$ ) and average alcohol intake before admission ( $\mathrm{t}$ value $=-1.31, \mathrm{p}=0.19$ ) was detected, subjects not included into the study had a significantly higher number of DSM-IV criteria of AD (not included $=5.33 \pm 1.0$ vs. included $=$ $5.08 \pm 1.1 ; \mathrm{t}$ value $=-3.94, \mathrm{p}<0.001)$.

In addition, lifetime axis I disorders were also assessed using these interviews and cross-checked with clinical files. Exclusion criteria included current axis I disorders including schizophrenia, schizoaffective, bipolar disorder, dementia and current suicidal behavior, since these patients were not admitted to open addiction treatment wards in all three hospitals. Alcohol-dependent subjects with current and lifetime major depression but without current suicidal behavior were included. Subjects incapable of informed consent were not enrolled into the study.

All assessments, with the exception of alcohol withdrawal at admission, were conducted approximately 2 weeks after detoxification from alcohol prior to patient's discharge. At this time, all subjects were still inpatients and free of any psychotropic medication. Characteristics of AD including DSM-IV criteria, amount of daily alcohol intake, duration of $\mathrm{AD}$, age at first drinking or rates of specific DSM-IV alcoholism criteria were assessed using the CIDI/DIA-X or the SSAGA.

Axis II disorders were assessed using the SCID-II-PQ self-rating questionnaires and a subsequent SCID-II interview of the positively endorsed items and specific PD diagnosis [German versions: 20]. The combined use of a self-rating screening tool to- 
gether with the interview has been reported to have good validity for axis II diagnosis [23].

To cross-check the axis I and axis II disorders assessed with CIDI, SSAGA and SCID-II, a comprehensive psychiatric examination was performed by experienced psychiatrists in each participating hospital (U.W.P., M.J., G.K., C.F.). Diagnosis of PD and intensity of PD traits were determined by summing up the positive items for each specific PD. Finally, the frequencies of cluster $\mathrm{A}, \mathrm{B}$ and $\mathrm{C} \mathrm{PD}$ s were ascertained.

All interviewers participated in an initial training using the CIDI, SSAGA and SCID-II. To differentiate between subjects with more and those with less severe $\mathrm{AD}$, a median split of the number of DSM-IV criteria endorsed and age at first drinking was performed.

\section{Ethical Standards}

A signed written informed consent was obtained from patients after complete and extensive description of the study. The Ethics Committees of all three institutions (Universities of Mainz, Regensburg and Munich) approved the study.

\section{Statistics}

All continuous data were tested for normal distribution using the Kolmogorov-Smirnov nonparametric test. The differences in continuous variables like age and number of AD criteria endorsed across groups (PD vs. no PD diagnosis) were computed using Student's $t$ test for independent samples or one-way ANOVA when the three recruitment sites were compared. Comparisons of dichotomous variables like gender between groups were conducted using $\chi^{2}$ statistics. A two-tailed alpha-significance level of $\mathrm{p}=0.05$ was defined to be statistically significant.

A series of logistic regressions was employed to evaluate how PD characteristics influenced AD severity in the context of all relevant PDs. Axis II diagnoses were entered simultaneously into the equation together with age and gender. A median split of the number of DSM-IV criteria endorsed and age at first drinking were employed as dependent variables.

\section{Results}

\section{Sample Characteristics}

Sample characteristics across centers are summarized in table 1. All participants were of German descent from the south and southwest of Germany.

PD diagnoses were detected in 652 individuals $(60.4 \%$, females $=128$ of 231 57.7\%; males $=524$ of 848, 61.8\%). However, the PD diagnoses rates significantly differed across centers. While 239 (61.9\%) of Munich inpatients and 60 (29.7\%) of Mainz inpatients received at least one PD diagnosis, the highest PD rate was found for Regensburg inpatients $(n=353 ; 71.9 \%)$ (overall $\left.\chi^{2}=107.10, p<0.001\right)$. No significant difference was detected regarding the rate of PD diagnoses between genders $\left(\chi^{2}=0.10 ; p=0.76\right)$.

As demonstrated in table 1 , subjects with $\mathrm{AD}$ and $\mathrm{PD}$ fulfilled more criteria of $\mathrm{AD}$ and lived more often alone.
All alcohol-dependent individuals had an average of 5.43 \pm 1.44 DSM-IV AD criteria (median $=6.00$ ). Performing a median-split, 477 (44.2\%) subjects were included in the group with 7 DSM-IV criteria endorsed and the remaining individuals (55.8\%) in the group with less than 7 criteria endorsed. Average age at first alcohol drinking was $16.89 \pm 5.9$ years (Median 16.00). The group with a younger age at first drinking comprised 432 (40.0\%) individuals, and the remaining subjects were included in the group with later drinking onset (60.0\%).

\section{PD Clusters and Characteristics of AD and Other Psychiatric Comorbidity}

Comparing subjects with specific cluster A, B and C PD diagnosis, as demonstrated in table 1 , individuals with cluster B PDs had the most severe characteristics of $\mathrm{AD}$ and social impairment: they were more frequently unemployed and more often lived alone. In comparison, more DSM-IV criteria of AD were endorsed in alcoholdependent individuals with cluster C PD compared to subjects without any cluster $\mathrm{C}$ diagnosis. Patients with cluster A PDs reported more DSM-IV criteria of AD and more severe social consequences compared to cluster B and $\mathrm{C}$ subjects, but did not have higher alcohol intake before admission and lived significantly more often alone.

However, rates of axis II diagnoses and characteristics of AD differed significantly across sites. Several factors may account for these differing results. First, despite typical admission strategies of treatment-seeking, alcoholdependent individuals in Germany and inpatient treatment, selection bias for each site cannot be excluded. It may make a difference in the rate of PDs if the alcoholdependent individuals are treatment seeking and admitted via a motivational group (Munich site), an outpatient unit (Regensburg site) or admitted for emergency detoxification (Mainz site). Furthermore, subjects of the Regensburg site endorsed more criteria of $\mathrm{AD}$ and might therefore have a higher rate of PDs. Interrater differences in assessment of PD may have contributed to the differences in axis II disorders across sites. Differences in characteristics of $\mathrm{AD}$ may arise from different assessment methods employed across sites (CIDI vs. SSAGA) even when all participating study centres used ICD10 and DSM-IV diagnostic criteria. While assessing the same characteristics, even slight differences in phrasing the questions may result in significant differences in the responses obtained. Furthermore, subjects from the Regensburg site had a higher number of DSM-IV AD criteria endorsed which might also result in a higher rate of PDs compared to subjects recruited in Munich or Mainz. 
Table 1. Characteristics of alcohol-dependent individuals with and without PD and PD clusters (mean \pm SD)

\begin{tabular}{|c|c|c|c|c|c|c|c|c|}
\hline & \multicolumn{8}{|c|}{ Axis II disorders and cluster } \\
\hline & \multicolumn{2}{|c|}{ alcohol-dependent subjects } & \multicolumn{2}{|l|}{ cluster A } & \multicolumn{2}{|l|}{ cluster B } & \multicolumn{2}{|l|}{ cluster C } \\
\hline & $\begin{array}{l}\text { with PD } \\
\mathrm{n}=652 \\
(60.4 \%)\end{array}$ & $\begin{array}{l}\text { without PD } \\
\mathrm{n}=427 \\
(39.6 \%)\end{array}$ & yes & no & yes & no & yes & no \\
\hline Age & $\begin{array}{l}42.83 \pm \\
9.5\end{array}$ & $\begin{array}{r}45.09 \pm \\
9.8^{* * * *}\end{array}$ & $\begin{array}{c}40.86 \pm \\
9.0\end{array}$ & $\begin{array}{r}44.62 \pm \\
9.8^{* * *}\end{array}$ & $\begin{array}{c}41.80 \pm \\
9.3\end{array}$ & $\begin{array}{r}45.00 \pm \\
9.7^{* * *}\end{array}$ & $\begin{array}{l}43.50 \pm \\
9.8\end{array}$ & $\begin{array}{c}43.86 \pm \\
9.6\end{array}$ \\
\hline Age at onset AD & $\begin{array}{l}29.91 \pm \\
10.0\end{array}$ & $\begin{array}{r}32.29 \pm \\
9.8^{* * * *}\end{array}$ & $\begin{array}{c}29.36 \pm \\
9.6\end{array}$ & $\begin{array}{l}31.29 \pm \\
10.1^{*}\end{array}$ & $\begin{array}{c}28.53 \pm \\
9.6\end{array}$ & $\begin{array}{r}32.46 \pm \\
9.9^{* * * *}\end{array}$ & $\begin{array}{l}30.36 \pm \\
10.3\end{array}$ & $\begin{array}{c}31.13 \pm \\
9.7\end{array}$ \\
\hline Age at first drinking & $\begin{array}{c}16.1 \pm \\
5.5\end{array}$ & $\begin{array}{c}16.86 \pm \\
6.0\end{array}$ & $\begin{array}{c}16.59 \pm \\
5.1\end{array}$ & $\begin{array}{c}16.50 \pm \\
5.9\end{array}$ & $\begin{array}{c}16.04 \pm \\
5.6\end{array}$ & $\begin{array}{c}16.83 \pm \\
5.7^{*}\end{array}$ & $\begin{array}{c}16.48 \pm \\
5.5\end{array}$ & $\begin{array}{c}16.63 \pm \\
6.0\end{array}$ \\
\hline Mean alcohol intake, g/day & $\begin{array}{l}301.25 \pm \\
165.8\end{array}$ & $\begin{array}{l}253.54 \pm \\
141.8^{* * *}\end{array}$ & $\begin{array}{l}313.62 \pm \\
173.3\end{array}$ & $\begin{array}{l}272.41 \pm \\
148.8^{* *}\end{array}$ & $\begin{array}{l}312.90 \pm \\
174.1\end{array}$ & $\begin{array}{l}261.89 \pm \\
144.1^{* * *}\end{array}$ & $\begin{array}{l}298.83 \pm \\
161.3\end{array}$ & $\begin{array}{l}269.73 \pm \\
149.2^{* * *}\end{array}$ \\
\hline Duration of AD & $\begin{array}{c}12.53 \pm \\
9.4\end{array}$ & $\begin{array}{c}12.19 \pm \\
8.7\end{array}$ & $\begin{array}{c}11.19 \pm \\
8.2\end{array}$ & $\begin{array}{c}12.78 \pm \\
9.5^{*}\end{array}$ & $\begin{array}{c}12.91 \pm \\
9.5\end{array}$ & $\begin{array}{c}12.01 \pm \\
8.9\end{array}$ & $\begin{array}{c}12.67 \pm \\
9.6\end{array}$ & $\begin{array}{c}12.20 \pm \\
8.8\end{array}$ \\
\hline DSM IV criteria & $\begin{array}{l}5.89 \pm \\
1.3\end{array}$ & $\begin{array}{l}5.42 \pm \\
1.5^{* * *}\end{array}$ & $\begin{array}{l}6.06 \pm \\
1.2\end{array}$ & $\begin{array}{l}5.60 \pm \\
1.4^{* * *}\end{array}$ & $\begin{array}{l}5.92 \pm \\
1.2\end{array}$ & $\begin{array}{l}5.56 \pm \\
1.5^{* * *} \\
\end{array}$ & $\begin{array}{l}5.94 \pm \\
1.3 \\
\end{array}$ & $\begin{array}{l}5.53 \pm \\
1.5^{* * *}\end{array}$ \\
\hline \multicolumn{9}{|l|}{ Categorical variables } \\
\hline Unemployed & $57.4 \%$ & $56.1 \%$ & $55.3 \%$ & $57.0 \%$ & $53.5 \%$ & $58.5 \%$ & $59.3 \%$ & $54.7 \%$ \\
\hline Living alone & $46.6 \%$ & $32.6 \% * * *$ & $50.0 \%$ & $39.3 \% *$ & $50.6 \%$ & $35.5 \% * * *$ & $43.0 \%$ & $41.5 \%$ \\
\hline Tolerance & $85.0 \%$ & $76.9 \% * * *$ & $89.1 \%$ & $79.7 \% * *$ & $85.6 \%$ & $79.0 \% * *$ & $86.6 \%$ & $78.9 \% * *$ \\
\hline Physical withdrawal & $81.4 \%$ & $79.4 \%$ & $81.0 \%$ & $80.3 \%$ & $81.7 \%$ & $79.9 \%$ & $81.4 \%$ & $79.7 \%$ \\
\hline Alcohol in larger amounts & $93.7 \%$ & $83.4 \% * * *$ & $95.5 \%$ & $88.1 \% * *$ & $94.3 \%$ & $86.9 \% * * *$ & $95.0 \%$ & $86.3 \% * * *$ \\
\hline Unsuccessful cut down & $93.6 \%$ & $88.4 \% * *$ & $92.8 \%$ & $91.4 \%$ & $92.1 \%$ & $91.1 \%$ & $95.7 \%$ & $88.6 \%$ *** \\
\hline Time getting substance & $65.9 \%$ & $58.8 \% *$ & $70.6 \%$ & $60.8 \% *$ & $67.5 \%$ & $59.5 \% *$ & $65.0 \%$ & $61.5 \%$ \\
\hline Given up activities & $78.3 \%$ & $65.2 \% * * *$ & $80.6 \%$ & $70.7 \% * *$ & $78.4 \%$ & $69.7 \%^{* *}$ & $79.7 \%$ & $68.0 \% * * *$ \\
\hline Alcohol use is continued & $90.8 \%$ & $88.8 \%$ & $93.2 \%$ & $89.0 \% *$ & $92.8 \%$ & $88.2 \% *$ & $90.2 \%$ & $89.3 \%$ \\
\hline Delirium history & $15.5 \%$ & $15.4 \%$ & $15.9 \%$ & $15.3 \%$ & $16.4 \%$ & $14.9 \%$ & $16.5 \%$ & $15.0 \%$ \\
\hline Seizure history & $19.0 \%$ & $18.3 \%$ & $16.9 \%$ & $19.2 \%$ & $19.1 \%$ & $18.0 \%$ & $19.3 \%$ & $18.0 \%$ \\
\hline Liver disease & $33.5 \%$ & $30.2 \%$ & $35.3 \%$ & $31.4 \%$ & $34.5 \%$ & $30.5 \%$ & $35.7 \%$ & $30.5 \%$ \\
\hline Pancreas disease & $7.7 \%$ & $11.1 \%$ & $7.4 \%$ & $9.5 \%$ & $8.2 \%$ & $9.7 \%$ & $8.4 \%$ & $9.6 \%$ \\
\hline
\end{tabular}

\section{Effects of Gender on Rate of PDs and Their Influence} on AD Characteristics

As presented in table 2, the most frequent PDs diagnosed in the sample were obsessive-compulsive, borderline and narcissistic PDs followed by paranoid and antisocial PD.

Significant gender differences in the rate of axis II disorders were found for cluster B disorders. Females received significantly more often a diagnosis of borderline $\mathrm{PD}$, while males had higher rates of antisocial and narcissistic PD. Depressive and histrionic PD were more often diagnosed in females compared to males, but did not reach statistical significance.

Females and males with a PD (PD+) diagnosis were significantly younger than those without $\mathrm{PD}$ diagnosis
(PD-) (males $\mathrm{PD}+=43.10 \pm 9.4$ vs. $\mathrm{PD}-=44.78 \pm 9.7$; females $\mathrm{PD}+=41.89 \pm 10.1$ vs. $\mathrm{PD}-=45.91 \pm 10.0$ years), had a higher daily alcohol intake (males $\mathrm{PD}+=$ $316.37 \pm 169.5$ vs. $\mathrm{PD}-=272.06 \pm 149.4$; females $\mathrm{PD}+=$ $227.45 \pm 112.2$ vs. $\mathrm{PD}-=182.38 \pm 77.5 \mathrm{~g} /$ day), a higher number of DSM-IV AD criteria endorsed (males PD+ = $5.90 \pm 1.3$ vs. $\mathrm{PD}-=5.40 \pm 1.6$; females $\mathrm{PD}+=5.77 \pm$ 1.4 vs. PD- $=5.32 \pm 1.6)$ and consumed more often alcohol in larger amounts (males $\mathrm{PD}+=93.1 \%$ vs. $\mathrm{PD}-=$ $83.3 \%$; females $\mathrm{PD}+=96.5 \%$ vs. $\mathrm{PD}-=84.8 \%$ ). Males with an axis II disorder had a significantly earlier age of alcoholism onset $(\mathrm{PD}+=29.33 \pm 9.9$ vs. $\mathrm{PD}-=31.61 \pm$ 9.8), more often lived alone $(\mathrm{PD}+=49.8 \%$ vs. $\mathrm{PD}-=$ $33.7 \%$ ), reported a higher rate of tolerance (PD+ $=86.6 \%$ vs. PD- $=76.0 \%$ ), unsuccessful attempts to cut down 
drinking $(\mathrm{PD}+=93.5 \%$ vs. $\mathrm{PD}-=87.8 \%)$ and giving up important activities (PD+ $=78.7 \%$ vs. $\mathrm{PD}-=63.5 \%$ ). The group of females with PD were significantly younger at first drinking $(\mathrm{PD}+=16.99 \pm 6.5$ vs. $\mathrm{PD}-=19.81 \pm$ 10.1).

When all males and females of the sample are compared, males were significantly younger at first drinking (males $=16.10 \pm 4.8$ vs. females $=18.11 \pm 8.2$ years $)$ while females were significantly older at $\mathrm{AD}$ onset (males $=30.10 \pm 9.9$ vs. females $=33.59 \pm 9.9$ years $)$, consumed a smaller amount of alcohol daily (males = $302.64 \pm 165.3$ vs. females $=209.42 \pm 102.2 \mathrm{~g} /$ day $)$, had a shorter duration of $\mathrm{AD}$ (males $=13.18 \pm 9.3 \mathrm{vs}$. females $=9.19 \pm 8.0$ years), lived less often alone (males = $44.8 \%$ vs. females $=31.6 \%$ ), reported less often ever having a withdrawal syndrome (males $=82.1 \%$ vs. females $=$ $74.1 \%$ ) and had less often an alcohol-induced pancreatic disease $($ males $=10.4 \%$ vs. females $=3.1 \%)$.

\section{Influence of PDs on AD Severity Using Multivariate}

Statistics

To assess the influence of PD characteristics on severity of $\mathrm{AD}$, assessed with number of DSM-IV criteria endorsed and age at first drinking, two logistic regression analyses were conducted. In a first step, PD diagnoses, gender and age were entered together into the equation with a median split of number of DSM-IV criteria endorsed as the dependent variable.

The results are depicted in table 3 . The first equation explained $3.3 \%$ of variance. While none of the sociodemographic measures remained in the equation, a significant influence of obsessive-compulsive and schizoid PD on higher number of DSM-IV AD criteria endorsed was revealed. In the second analysis which considered a median split of age at first drinking as the dependent variable, female gender, older age and negativistic PD significantly decreased the risk for early drinking whereas antisocial PD increased the risk. The second regression analysis explained $9.2 \%$ of the variance. The results remained mainly unchanged when current or lifetime history of major depression was added as an independent variable to both equations.

In a further analysis, multinomial logistic regression models were computed to use polychotomized response variables (number of DSM-IV criteria endorsed and age at first drinking) as dependent variables. We divided the two dependent variables into quartiles to exploit their variance as best as possible despite their unfavorable distribution characteristics. To reduce complexity and achieve higher parsimony, these models were recomput-
Table 2. Frequencies of PDs in inpatient male and female alcoholdependent subjects

\begin{tabular}{lrrrrc}
\hline $\begin{array}{l}\text { PD and } \\
\text { axis II cluster }\end{array}$ & $\begin{array}{l}\text { Total, \% } \\
(\mathrm{n}=1,079)\end{array}$ & $\begin{array}{l}\text { Males, \% } \\
(\mathrm{n}=848)\end{array}$ & $\begin{array}{l}\text { Females, \% } \\
(\mathrm{n}=231)\end{array}$ & $\begin{array}{l}\chi^{2} \\
\text { value }\end{array}$ & $\begin{array}{l}\text { Signifi- } \\
\text { cance } \\
\text { O’ vs. } 9\end{array}$ \\
\hline Cluster A & & & & & \\
Paranoid & 17.8 & 18.5 & 15.4 & 1.16 & 0.28 \\
Schizotypal & 5.3 & 5.0 & 6.8 & 1.09 & 0.29 \\
Schizoid & 4.1 & 4.4 & 3.2 & 0.68 & 0.41 \\
\hline Cluster B & & & & & \\
Histrionic & 1.1 & 0.8 & 2.3 & 3.13 & 0.08 \\
Narcissistic & 18.6 & 21.1 & 9.9 & 14.37 & $<0.001$ \\
Borderline & 26.1 & 24.5 & 31.7 & 4.69 & 0.03 \\
Antisocial & 15.9 & 17.2 & 9.9 & 7.13 & 0.008 \\
\hline Cluster C & & & & & \\
Avoidant & 11.1 & 10.3 & 14.0 & 2.33 & 0.13 \\
Dependent & 5.4 & 5.8 & 3.2 & 2.44 & 0.12 \\
Obsessive & 31.4 & 31.5 & 32.0 & 0.02 & 0.90 \\
Negativistic & 8.8 & 9.1 & 8.1 & 0.21 & 0.64 \\
Depressive & 8.0 & 7.3 & 10.9 & 3.04 & 0.08 \\
\hline
\end{tabular}

ed using percentiles of the dependent variables. The results for both dependent variables, however, did not yield other significant predictors as in the models using dichotomized dependent variables.

\section{Discussion}

The first aim of this analysis of a larger sample of inpatient alcohol-dependent individuals was to assess the prevalence of the full range of DSM-IV PDs and their association with $\mathrm{AD}$ characteristics. As with previous research, approximately $60 \%$ of the inpatients received an additional diagnosis of at least one PD. Not surprisingly, this rate is significantly higher than in epidemiologic samples [4] like the NESARC sample but within the PD prevalence range of 25 to $93 \%$ of other inpatient samples [5]. Alcohol-dependent inpatients undergoing treatment were suggested to be more severely affected by comorbid psychiatric disorders, including PDs [5].

Comparing these results to rates of PDs in a previous sample of hospitalized alcohol-dependent individuals using DSM-III-R criteria, a higher rate (78\%) of axis II diagnosis was found in individuals with ASUD [24]. Previous research found histrionic (34\%), dependent (29\%), avoidant (19\%) and borderline PD (17\%) to be the most common axis II diagnoses [24]. The current study de- 
Table 3. Logistic regression analyses of PDs significantly associated with severity of AD (number of DSM-IV criteria endorsed and age at first drinking)

\begin{tabular}{|c|c|c|c|c|c|c|}
\hline \multirow{2}{*}{$\begin{array}{l}\text { Variables } \\
(\mathrm{n}=1,079)\end{array}$} & \multicolumn{3}{|c|}{ Number of DSM-IV criteria } & \multicolumn{3}{|c|}{ Age at first drinking } \\
\hline & $\chi^{2}$ value & OR & $95 \% \mathrm{CI}$ & $\chi^{2}$ value & OR & $95 \% \mathrm{CI}$ \\
\hline Gender & 2.15 & 0.77 & $0.54-1.09$ & $4.29^{*}$ & 0.70 & $0.49-0.98$ \\
\hline Age & 0.84 & 0.99 & $0.98-1.01$ & $31.19^{* * *}$ & 0.96 & $0.95-0.97$ \\
\hline Paranoid PD & 0.21 & 1.16 & $0.75-1.72$ & 0.15 & 0.92 & $0.60-1.40$ \\
\hline Schizotypal PD & 2.15 & 0.77 & $0.61-2.21$ & 1.29 & 1.45 & $0.76-2.76$ \\
\hline Schizoid PD & $6.51^{*}$ & 2.38 & $1.22-4.62$ & 0.31 & 0.82 & $0.41-1.65$ \\
\hline Histrionic PD & 2.64 & 3.30 & $0.78-13.97$ & 2.31 & 0.32 & $0.07-1.39$ \\
\hline Narcissistic PD & 2.26 & 0.74 & $0.50-1.10$ & 0.01 & 0.98 & $0.66-1.46$ \\
\hline Borderline PD & 0.50 & 1.14 & $0.79-1.64$ & 0.009 & 1.00 & $0.69-1.44$ \\
\hline Antisocial PD & 0.02 & 0.97 & $0.65-1.45$ & $17.62^{* * *}$ & 2.30 & $1.56-3.40$ \\
\hline Avoidant PD & 0.63 & 1.23 & $0.74-2.03$ & 0.06 & 0.94 & $0.56-1.56$ \\
\hline Dependent PD & 1.74 & 1.55 & $0.81-2.97$ & 0.90 & 0.72 & $0.36-1.43$ \\
\hline Obsessive-compulsive PD & $9.53^{* *}$ & 1.57 & $1.18-2.10$ & 1.13 & 1.18 & $0.87-1.61$ \\
\hline Negativistic PD & 0.00 & 1.01 & $0.59-1.74$ & $5.65^{*}$ & 0.55 & $0.33-0.90$ \\
\hline Depressive PD & 0.52 & 0.81 & $0.45-1.45$ & 1.00 & 0.74 & $0.41-1.33$ \\
\hline
\end{tabular}

${ }^{*} \mathrm{p}<0.05 ;{ }^{* *} \mathrm{p}<0.01 ;{ }^{* *} \mathrm{p}<0.001$. The variance explained in the first logistic regression equation was $3.3 \%$ $\left(\mathrm{R}^{2}\right.$ value 31.7, d.f. $\left.=14, \mathrm{p}=0.004\right), 9.2 \%$ for the second regression equation $\left(\mathrm{R}^{2}\right.$ value $=73.7$, d.f. $=14, \mathrm{p}<$ 0.001).

tected a different, but overlapping profile of most frequent PDs. Obsessive-compulsive (31.4\%), borderline (26.1\%), narcissistic (18.6\%) and paranoid PD (17.8\%) were the four most common axis II disorders. Variations in rates of specific PDs across studies might be due to differences in specific sample characteristics (e.g. inpatient vs. outpatient vs. epidemiologic) [4], assessment methods [25] and setting of addiction treatment facilities [26]. Some PDs, i.e. paranoid, borderline, antisocial and obsessive-compulsive PDs, are diagnosed most frequently in alcohol-dependent individuals across studies [16, 27].

Also in line with previous research is the association of PD with selected AD characteristics. Several recent studies reported an earlier onset and more severe characteristics of $\mathrm{AD}$ in personality disordered individuals [28, 29]. In particular, subjects with antisocial PD were reported to have worse long-term outcome and increased likelihood of treatment failure $[9,30]$. Using two different potential assessments of $\mathrm{AD}$ severity in logistic regression analyses, the number of DSM-IV criteria endorsed and age at first drinking, the former was found to be significantly related to schizoid and obsessive-compulsive $\mathrm{PD}$ and the latter to be significantly related to antisocial personality. Antisocial personality disorder characteristics, among other factors, have been related in previous research with the initiation of drinking $[31,32]$. The num- ber of DSM-IV criteria, though in part reflecting the severity of $\mathrm{AD}$, may be related to other factors like comorbidity with obsessive-compulsive and schizoid PD.

The current study identifies specific characteristics of sociodemography and AD for PD clusters. These profiles may facilitate clinical risk assessment for comorbid alcohol-dependent and PD subjects. Since cross-sectional studies cannot determine the full picture of relationships between comorbid PDs and AD over time, prospective studies in comorbid subjects with $\mathrm{AD}$ and PDs are needed.

Significant gender differences in rates of PDs are present in cluster B disorders only. While males more often met criteria for antisocial and narcissistic disorders, females had more borderline PDs, in line with previous reports on different gender rates of cluster B PDs in alcoholdependent subjects [33]. These gender differences in rates of PD, however, contributed little to the sex-specific influence axis II diagnoses have on $\mathrm{AD}$ characteristics. Though several of these characteristics are significantly different between genders, including age at first drinking, duration of $\mathrm{AD}$ or daily alcohol intake, both genders hold a more severe profile of $\mathrm{AD}$ when they also have a comorbid axis II diagnosis. While antisocial PD is in general more often found in males, our results indicate that approximately $10 \%$ of females have antisocial $\mathrm{PD}$ which 
influences the severity of $\mathrm{AD}$, as do other comorbid axis II disorders.

The results must be considered in light of some caveats. First, the study collected cross-sectional data from alcohol-dependent inpatients at three different university addiction treatment facilities in Germany. While PDs were assessed using the same instrument (SCID II), other AD characteristics were obtained using two different interviews (CIDI and SSAGA). Further, the different rates of PDs across centers may arise from more severe characteristics of $\mathrm{AD}$ in one of the hospitals (Regensburg), potentially resulting in a higher rate of subjects with psychiatric comorbidity of axis II disorders.

Though all centers recruited subjects consecutively, certain individuals could not be recruited for the study. Comparing the available characteristics of subjects enrolled and those not included into the study, while no differences were found in gender, age and some of the $\mathrm{AD}$ characteristics, those patients not included had a higher number of DSM-IV AD criteria. This may indicate that they may be more severely affected by other psychiatric and/or somatic disorders, or have an even higher rate of PDs making them less compliant and less likely to participate in inpatient studies.

Since individuals with axis I disorders, except depression, are not treated in open 'qualified detoxification' wards in Germany, subjects with schizophrenia, schizoaffective or bipolar disorders were excluded from the study, hence limiting the generalizability of the study findings to in- and outpatient samples of treatment-seeking alcohol-dependent subjects. Since the study recruited treatment-seeking alcohol-dependent subjects, no history of criminality was obtained. Furthermore, severity of AD was assessed using only the number of DSM-IV criteria endorsed. There are other measures of addiction severity not used, e.g. Addiction Severity Index [19].

\section{References}

$>1$ Regier DA, Farmer ME, Rae DS, Locke BZ, Keith SJ, Judd LL, Godwin FK: Comorbidity of mental disorders with alcohol and other drug abuse: results from the Epidemiologic Catchment Area (ECA) Study. JAMA 1990; 264:2511-2518.

$\checkmark 2$ Ross HE, Galser FB, Germanson T: The prevalence of psychiatric disorders in patients with alcohol and other drug problems. Arch Gen Psychiatry 1988;45:1023-1031.

3 Verheul R, van den Brink W, Hartgers C: Prevalence of personality disorders among alcoholics and drug addicts: an overview. Eur Addict Res 1995;1:166-177.

4 Grant BF, Stinson FS, Dawson DA, Chou SP, Ruan WJ, Pickering RP: Cooccurrence of 12month alcohol and drug use disorders and personality disorders in the United States: results from the National Epidemiologic Survey on Alcohol and Related Conditions. Arch Gen Psychiatry 2004;61:361-368.

5 Preuss UW, Koller G, Barnow S, Eikmeier M, Soyka M: Suicidal behavior in alcohol-dependent subjects: the role of personality disorders. Alcohol Clin Exp Res 2006;30:866877.

6 Verheul R, Kranzler HR, Poling J, Tennen H, Ball S, Rounsaville BJ: Axis I and axis II disorders in alcoholics and drug addicts: fact or artifact? J Stud Alcohol 2000;61:101-110.

7 Stewart SH: Alcoholics in acute medical settings have increased risk for other drug, mood, and personality disorders. Int J Psy chiatry Med 2007;37:59-67.
8 Verheul R, Kranzler HR, Poling J, Tennen H, Ball S, Rounsaville BJ: Cooccurrence of Axis I and Axis II disorders in substance abusers. Acta Psychiatr Scand 2000;101:110-118.

$\checkmark$ Di Sclafani V, Finn P, Fein G: Psychiatric comorbidity in long-term abstinent alcoholic individuals. Alcohol Clin Exp Res 2007;31: 795-803.

10 Poldrugo F, Forti B: Personality disorders and alcoholism treatment outcome. Drug Alcohol Depend 1988;21:171-176

- 11 Bischof G, Rumpf HJ, Meyer C, Hapke U, John U: Influence of psychiatric comorbidity in alcohol-dependent subjects in a representative population survey on treatment utilization and natural recovery. Addiction 2005; 100:405-413.

12 Ralevski E, Ball S, Nich C, Limoncelli D, Petrakis I: The impact of personality disorders on alcohol-use outcomes in a pharmacotherapy trial for alcohol dependence and comorbid Axis I disorders. Am J Addict 2007; 16: 443-449.

13 van den Bosch LM, Verheul R, van den Brink W: Substance abuse in borderline personality disorder: clinical and etiological correlates. J Personal Disord 2001;15:416-424.

14 Saha TD, Chou SP, Grant BF: Toward an alcohol use disorder continuum using item response theory: results from the National Epidemiologic Survey on Alcohol and Related Conditions. Psychol Med 2006;36:931-941.

15 Moss HB, Chen CM, Yi HY: DSM-IV criteria endorsement patterns in alcohol dependence: relationship to severity. Alcohol Clin Exp Res 2008;32:306-313.
16 Ehlers CL, Slutske WS, Gilder DA, Lau P, Wilhelmsen KC: Age at first intoxication and alcohol use disorders in Southwest California Indians. Alcohol Clin Exp Res 2006;30: 1856-1865.

17 Hesselbrock MN, Hesselbrock VM, Segal B, Schuckit MA, Bucholz K: Ethnicity and psychiatric comorbidity among alcohol-dependent persons who receive inpatient treatment: African Americans, Alaska natives, Caucasians, and Hispanics. Alcohol Clin Exp Res 2003;27:1368-1373.

18 Hingson RW, Heeren T, Winter MR: Age of alcohol-dependence onset: associations with severity of dependence and seeking treatment. Pediatrics 2006;118:e755-e763.

19 McLellan AT, Luborski L, Cacciola J, Griffith J, McGRahan P, O'Brien CP: Addiction Severity Index. Philadelphia, University of Pennsylvania, VA Administration, Center for Studies of Addiction, 1992.

20 Wittchen HU, Kessler RC, Zhao S, Abelson JL: Reliability and clinical validity of UMCIDI DSM-III-R generalized anxiety disorder. J Psychiatr Res 1995;29:95-110.

21 Wittchen HU, Pfister H: DIA-X-Interviews: Manual fur Screening-Verfahren und Interview. Interviewheft Längsschnittuntersuchung (DIA-X-Lifetime), 2004.

22 Hesselbrock M, Easton C, Buchholz KK, Schuckit M, Hesselbrock V: A validity study of the SSAGA - a comparison with the SCAN. Addiction 1999;94:1361-1370. 
-23 Farmer RF, Chapman AL: Evaluation of DSM-IV personality disorder criteria as assessed by the structured clinical interview for DSM-IV personality disorders. Compr Psychiatry 2002;43:285-300.

-24 DeJong CA, van den Brink W, Harteveld FM, van der Wielen EG: Personality disorders in alcoholics and drug addicts. Compr Psychiatry 1993;34:87-94.

-25 Spitzer RL, Endicott J, Gibbon M: Crossing the border into borderline personality and borderline schizophrenia: development of criteria. Arch Gen Psychiatry 1979;36:1724.

-26 Verheul R, Hartgers C, Van den Brink W, Koeter MW: The effect of sampling, diagnostic criteria and assessment procedures on the observed prevalence of DSM-III-R personality disorders among treated alcoholics. J Stud Alcohol 1998;59:227-236.

-27 Driessen M, Veltrup C, Wetterling T, John U, Dilling H: Axis I and axis II comorbidity in alcohol dependence and the two types of alcoholism. Alcohol Clin Exp Res 1998;22:7786.
28 Bottlender M, Preuss UW, Soyka M: Association of personality disorders with type A and type B alcoholics. Eur Arch Psychiatry Clin Neurosci 2006;256:55-61.

-29 Goldstein RB, Dawson DA, Saha TD, Ruan WJ, Compton WM, Grant BF: Antisocial behavioral syndromes and DSM-IV alcohol use disorders: results from the National Epidemiologic Survey on Alcohol and Related Conditions. Alcohol Clin Exp Res 2007;31: 814-828.

30 Wagner T, Krampe H, Stawicki S, Reinhold J, Jahn H, Mahlke K, Barth U, Sieg S, Maul O, Galwas C, Aust C, Kroner-Herwig B, Brunner E, Poser W, Henn F, Ruther E, Ehrenreich $\mathrm{H}$ : Substantial decrease of psychiatric comorbidity in chronic alcoholics upon integrated outpatient treatment: results of a prospective study. J Psychiatr Res 2004;38:619635.
31 Kuperman S, Chan G, Kramer JR, Bierut L, Bucholz KK, Fox L, Hesselbrock V, Numberger JI Jr, Reich T, Reich W, Schuckit MA: Collaborative Study on the Genetics of Alcoholism Relationship of age of first drink to child behavioral problems and family psychopathology. Alcohol Clin Exp Res 2005; 29:1869-1876.

32 McGue M, Iacono WG, Legrand LN, Malone S, Elkins I: Origins and consequences of age at first drink. I. Associations with substanceuse disorders, disinhibitory behavior and psychopathology, and P3 amplitude. Alcohol Clin Exp Res 2001;25:1156-1165.

33 Morgenstern J, Langenbucher J, Labouvie E, Miller KJ: The comorbidity of alcoholism and personality disorders in a clinical population: prevalence rates and relation to alcohol typology variables. J Abnorm Psychol 1997; 106:74-84.

>34 Wu LT, Kouzis AC, Leaf PJ: Influence of comorbid alcohol and psychiatric disorders on utilization of mental health services in the National Comorbidity Survey. Am J Psychiatry 1999;156:1230-1236. 